\title{
Ophthalmological Significance of HLA Associated Uveitis
}

\author{
T. E. W. FELTKAMP \\ Amsterdam
}

\begin{abstract}
Summary
The association between HLA-A29 and birdshot chorioretinopathy is the strongest association between HLA and disease ever described. The determination of HLA-A29 is therefore of diagnostic significance.

The association between HLA-B27 and acute anterior uveitis (AAU) is much weaker. However, it is evident that $B 27^{+} \mathrm{AAU}$ is clinically different from $\mathrm{B27}^{-} \mathrm{AAU}$. Half of the $B 27^{+}$AAU patients have or will have ankylosing spondylitis or Reiter's syndrome. The determination of HLA-B27 is therefore of clinical significance and should be determined in each case of AAU. The $B 27^{+}$patients should be referred to a rheumatologist.

The determination of HLA-Bw51 is of limited but significant diagnostic value for the diagnosis of Behçet's disease in countries around the Mediterranean Sea or Japan. In Northern Europe HLA-Bw51 determination will not give much practical information.

The structure and function of HLA class I molecules is now known. It is probable that HLA-A29 and HLA-B27 molecules are directly involved in the pathogenesis of respectively birdshot chorioretinopathy and AAU
\end{abstract}

Associations between certain gene products of the so-called major histocompatibility complex (MHC), i.e. the human leucocyte antigens (HLA) and diseases have been described in great numbers. In this paper the practical consequences of associations between HLA and several kinds of uveitis will be discussed.

This will show that certain HLA types can serve as a diagnostic tool. Some HLA types can be used to divide clinical entities in diseases with a distinct pathogenesis. Finally, some attention will be paid to the role which some HLA molecules may play in the pathogenesis of the associated diseases.

\section{HLA System}

The genetic information on the formation of HLA molecules is localised on the short arm
Table I HLA allotypes*

\begin{tabular}{|c|c|c|c|c|c|}
\hline \multicolumn{3}{|c|}{75 HLA class I allotypes } & \multicolumn{3}{|c|}{29 HLA class II allotypes } \\
\hline A1 & B7 & Cw1 & DR1 & DQw1 & DPw1 \\
\hline . & B8 & . & DR2 & DQw2 & . \\
\hline . & . & . & DR3 & & . \\
\hline . & B27.1 & . & DR4 & DQw4 & . \\
\hline . & B27.2 & . & . & . & \\
\hline . & B27.3 & . & . & . & DPw6 \\
\hline A29.1 & B27.4 & . & . & . & \\
\hline A 29.2 & B27.5 & . & . & . & \\
\hline . 1 & B27.6 & . & . & DQw9 & \\
\hline . & B27HS & & . & & \\
\hline . & & Cw11 & . & & \\
\hline . & Bw51 & & . & & \\
\hline Aw74 & Bw77 & & DRw & & \\
\hline
\end{tabular}

*Only the first and last of each locus are given, together with the allotypes associated with ophthalmological diseases.

From: Netherlands Ophthalmic Research Institute and Central Laboratory for Bloodtransfusion Service, Amsterdam.

Correspondence to: T. E. W. Feltkamp, P.O. Box 12141, 1100 AC Amsterdam, The Netherlands. 
of chromosome 6 . The loci $\mathrm{A}, \mathrm{B}$ and $\mathrm{C}$ give rise to the formation of the allotypes of the socalled class I HLA molecules. The loci DP, DQ and DR carry the information for the allotypes of the class II molecules. The allo- types always come to expression and are mutually exclusive. In Table I the first and last allotypes for each locus are given, together with the allotypes which are associated with ophthalmological diseases. It should be noted

\section{Presentation of (viral?) peptides to cytotoxic T cells by HLA - class I molecules}

1. Intracellularly the just assembled HLA class I molecule presents the trough between the alpha helices to the agretope of the (viral?) peptide.
2. Intracellularly the agretope of the (viral?) peptide fits into the trough between the alpha helices of the HLA class I molecule.

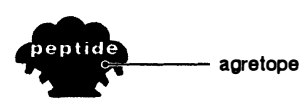

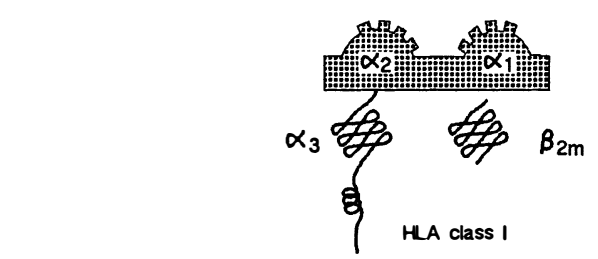

3. The HLA class I molecule plus peptide reaches the cell membrane and presents the epitope of the (viral?) peptide to the T cell receptor of cytotoxic $T$ cells.

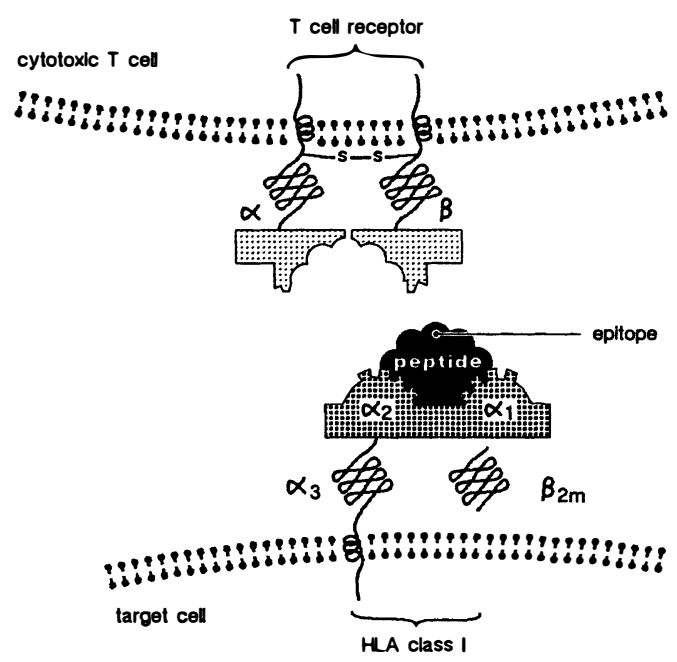

4. The epitope of the (viral?) peptide and the characteristic free surface of the alpha helices fit into the receptor of certain cytotoxic $T$ cells.

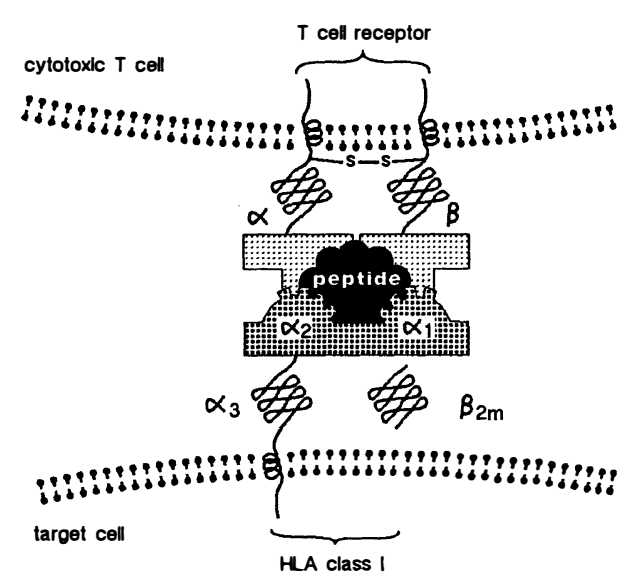

Fig. 1. Presentation of (viral?) peptides to cytotoxic T cells by HLA class I molecules (with permission of Neth J Med). ${ }^{1}$ 


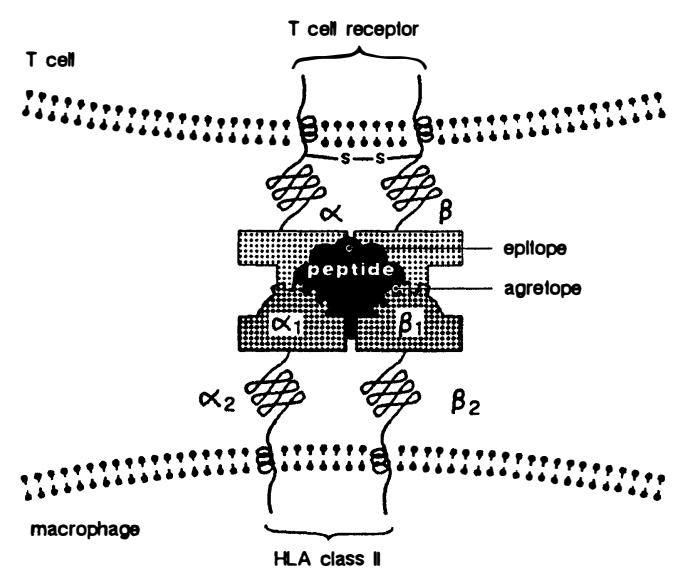

Fig. 2. Presentation of an antigenic peptide to a helper $T$ cell by an HLA class II molecule on the surface of a macrophage (with permission of $\mathrm{J}$ Head and Neck Pathol). ${ }^{2}$

that HLA-A29 is now split into two subtypes and HLA-B27 into seven subtypes.

HLA proteins of class I play an important role in the destruction of viral infected cells. Viral peptides probably fit with their agretope exactly in the groove between the two alphahelices which are situated on the alpha 1alpha 2 domain of the class I molecule (Fig. 1). When such a molecule reaches the cell surface together with the viral peptide, it may contact certain cytotoxic $\mathrm{T}$ lymphocytes having a receptor which fits both the epitope of the peptide and the characteristic surface of the alpha-helices of the HLA molecule. The specific cytotoxic $\mathrm{T}$ cell then becomes stimulated which leads to lysis of the peptide presenting cell.

HLA class II molecules play a comparable role in the presentation of antigens by macrophages or B cells to so-called helper T lymphocytes (Fig. 2). In this case the antigens are first phagocytosed and broken down to peptides. Some of these peptides then fit the HLA class II molecule. Both the class II molecule and the peptide then fit into the $T$ cell receptor of certain helper $\mathrm{T}$ lymphocytes. This leads to the production of interleukins which stimulate $\mathrm{B}$ cells and other $\mathrm{T}$ cells.

\section{HLA Types Associated with Uveitis}

The degree of association between an HLA type and a disease is expressed in the so-called relative risk (RR). This is the result of the number of positive patients in a certain group multiplied by the number of negative subjects in a group of healthy individuals of the same genetic background, divided by the number of negative patients times the number of positive controls.

\section{Birdshot chorioretinopathy}

The association between birdshot chorioretinopathy and HLA-A29 with an RR of 224 is the strongest of all HLA and disease associations (Table II). It is not yet evident whether one of the subtypes of A29 is even more strongly associated but even now, although genetic markers are, of course, not all 'invented' for such a purpose, A29 typing can be used as a diagnostic tool. It has a sensitivity, being the percentage of positive patients, of $96 \%$ (Table III). The specificity, being the percentage of negative controls, is $93 \%$. The likelihood ratio, being the sensitivity divided by 100 minus the specificity, is 14 . If this figure is introduced in a nomogram (Fig. 3) using Bayes' theorem, the contribution of the test to the increase of the probability of a certain diagnosis can be read., ${ }^{5,6,7}$ Figure 3 shows a supposed probability of $70 \%$ which rises to $97 \%$ if the patient is A29 positive. If the patient is A29 negative the probability drops from $70 \%$ to only $8.5 \%$.

\section{Acute anterior uveitis}

The association between HLA-B27 and AAU

Table II HLA associations with eye diseases in Europe. From Tiwari and Terasaki ${ }^{3}$ and Priem et al. ${ }^{4}$

\begin{tabular}{lllcrr}
\hline Disease & Country & $\begin{array}{c}\text { HLA } \\
\text { association }\end{array}$ & $\begin{array}{c}\text { Frequency } \\
\text { patients }\end{array}$ & $\begin{array}{c}\text { Frequency } \\
\text { controls }\end{array}$ & $R R$ \\
\hline Birdshot CRP & Benelux & A29 & $96 \%$ & $7 \%$ & 224 \\
Reiter's syndrome & Germ, Dan, Fr & B27 & $71 \%$ & $8 \%$ & 26 \\
AAU & Europe & B27 & $47 \%$ & $10 \%$ & 8 \\
Behçet's disease & Turkey & Bw51 & $82 \%$ & $23 \%$ & 14 \\
Behçet's disease & England & Bw51 & $21 \%$ & $12 \%$ & 2 \\
\hline
\end{tabular}


Table III HLA determination as diagnostic test

\begin{tabular}{|c|c|c|c|c|}
\hline & Sensitivity* & Specificity $\dagger$ & $\begin{array}{c}\text { Positive } \\
\text { likelihood ratio } \ddagger\end{array}$ & $\begin{array}{c}\text { Negative } \\
\text { likelihood ratio§ }\end{array}$ \\
\hline $\begin{array}{l}\text { HLA-A29/Birdshot CR } \\
\text { (Benelux) }\end{array}$ & $96 \%$ & $93 \%$ & 14 & 0.04 \\
\hline $\begin{array}{l}\text { HLA-B27/AAU } \\
\text { (England) }\end{array}$ & $56 \%$ & $93 \%$ & 8 & 0.47 \\
\hline $\begin{array}{l}\text { HLA-Bw51/Behçet } \\
\text { (Turkey) }\end{array}$ & $82 \%$ & $76 \%$ & 4 & 0.24 \\
\hline
\end{tabular}

*Sensitivity $=$ percentage positive patients.

$\dagger$ Specificity $=$ percentage negative controls.

$\ddagger$ Positive likelihood ratio = sensitivity: $(100$-specificity).

$\S$ Negative likelihood ratio $=(100$-sensitivity $)$ : specificity .

with an RR of 8 is not particularly high. However, this marker serves to split AAU into two kinds of uveitis, i.e. $B 27^{+} \mathrm{AAU}$ and B27 $7^{-} \mathrm{AAU} . \mathrm{B} 27^{+} \mathrm{AAU}$ is a disease occurring mainly in males. The onset is 10 years earlier than that of $\mathrm{B} 27^{-} \mathrm{AU}$. $\mathrm{B} 27^{+} \mathrm{AAU}$ in contrast to $\mathrm{B} 27^{-} \mathrm{AAU}$ is nearly always unilateral. $\mathrm{B} 27^{+} \mathrm{AAU}$ is more severe, i.e. with more fibrin and cells in the aqueous humor than B27- AAU. Mutton fat keratic precipitates are rare in $\mathrm{B} 27^{+} \mathrm{AAU}$. Finally, the $\mathrm{B} 27^{+} \mathrm{AAU}$ patients have a far greater chance of having or developing ankylosing spondylitis or Reiter's syndrome. ${ }^{8,9}$ AAU patients, therefore, have to be typed for HLA-B27. The $B 27^{+}$AAU patients should be referred to a rheumatologist even if they have no clinical symptoms of a joint disease since sacroiliitis is difficult to diagnose without radiological examination. ${ }^{10}$

HLA typing might not only lead to splitting of diseases which were previously considered as an entity, but also to lumping of groups of distinct diseases. Ankylosing spondylitis, Reiter's syndrome and other reactive arthritides due to infections with Salmonella, Shigella, Campylobacter, Yersinia or Chlamydia together with $\mathrm{B} 27^{+} \mathrm{AAU}$, are considered as 'B27 associated diseases' underlining a possible common pathogenic denominator and the clinical overlap. ${ }^{11}$

Even if AAU is considered despite the above as a clinical entity and if HLA-B27 is considered as a diagnostic aid, the sensitivity is only $56 \%$, the specificity $93 \%$ and the likelihood ratio 8 (Table III).

If this last figure was introduced in the nomogram of Figure 3, a supposed pre-test probability of $70 \%$ increased to $95 \%$ if the result of the B27 test was positive and decreased to $52 \%$ if the patient proved to be B27 negative.

\section{Behçet's disease}

The association between HLA-Bw51 and

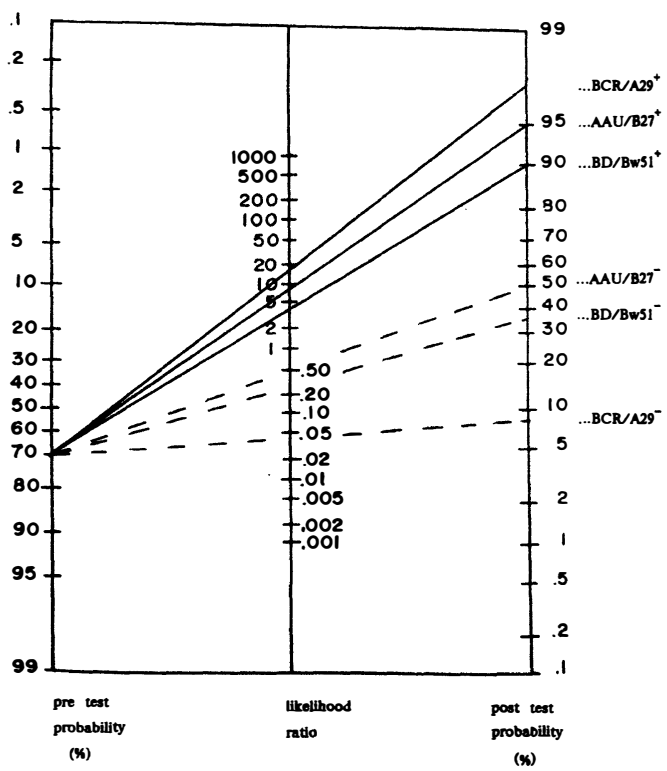

Fig. 3. Nomogram according to Fagan. ${ }^{6}$ If in the left scale the pre-test probability is introduced in percentages and in the middle scale the likelihood ratio, the interception between the line connecting these points and the right scale offers the post-test probability. The three lines drawn represent the examples given in the text for positive results of the HLA determination leading to an increase of the probability' The three broken lines represent the examples given in the text for negative results of the HLA determinations leading to a decrease of the probability. $B C R=$ birdshot chorioretinopathy; $B D=$ Behçet's disease (with permission of Int Ophthalmol). ${ }^{\text {? }}$ 
Table IV HLA association with some uveitides. From Ohno. ${ }^{12}$

$\left.\begin{array}{ll|l}\hline \text { Japan } & \text { Europe? } \\
\text { HLA-A24 } & \text { HLA-A1 } \\
\text { HLA-Bw54 } & \text { HLA-B8 } \\
\text { HLA-Dw15 } & \text { HLA-Cw7 } \\
\text { HLA-DR4 } & \text { HLA-Dw3 } \\
\text { HLA-DRw53 } & \text { HLA-Dr3 } \\
\text { HLA-DQw4 } & \text { HLA-DQw2 }\end{array}\right\}$\begin{tabular}{l} 
Vogt-Koyanagi-Harada syndrome \\
$\begin{array}{l}\text { Possner-Schlossman glaucomacyclitis crisis } \\
\text { Sympathetic ophthalmia }\end{array}$ \\
\hline
\end{tabular}

Behçet's disease with an RR of only 14 , is much lower than that between birdshot chorioretinopathy and HLA-A29, but much higher than the association betwen AAU and HLA-B27. This RR of 14 only pertains for Turkey. In other parts of Europe much lower figures are found (Table II). In Turkey the sensitivity of the Bw51 determination is $82 \%$ and the specificity $76 \%$. If the likelihood ratio of 4 is introduced into the nomogram of Figure 3 it can be seen that a supposed pre-test probability increases to $90 \%$ if the result of the Bw51 determination is positive. If this test is negative, the probability drops to only $36 \%$.

\section{Other uveitides}

In Japan the Vogt-Koyanagi-Harada syndrome, Possner-Schlossman's glaucoma cyclitis crisis and sympathetic ophthalmia were shown to be associated with HLA types which in the Far East are associated with increased immune responses and autoimmunity. ${ }^{12}$ In Europe such HLA types are those given in Table IV. Further studies are necessary before these associations can be considered to be of any clinical significance.

\section{Other Genetic Factors}

Family studies in AAU have revealed that after HLA-B27 other genetic factors must have a considerable influence. Linssen et al. showed that the prevalence of AAU in the normal Dutch population is about $0.2 \%$. In those with $\mathrm{B} 27^{+}$the prevalence is about $1 \% .{ }^{13}$ Derhaag et al. ${ }^{14}$ showed, however, that the chance of developing AAU in a $\mathrm{B} 27^{+}$person with a relative who is also $\mathrm{B} 27^{+}$and once having AAU is $13 \%$. If this person is over 45 years old, the chance of having or developing AAU rises to $22 \%$. Other genetic factors therefore must play a pathogenetic role.

The other genetic pathogenetic factors are probably not localised on the short arm of chromosome $6,{ }^{15}$ nor on the tip of the long arm of chromosome $14 .{ }^{16}$ Finally, it is probable that more than one subtype of HLA-B27 is in fact associated with AAU. ${ }^{17}$

\section{Pathogenic Role of HLA Class I Molecules}

The extremely strong associations between HLA-A29 and birdshot chorioretinopathy on the one hand and HLA-B27 and AAU on the other, suggested that these HLA class I molecules might play a direct pathogenetic role in these diseases. Of interest in this respect is the finding that at least in AAU the distribution of the subtypes is similar to the normal population. ${ }^{17}$ If AAU is indeed equally associated with all HLA-B27 subtypes and not with the HLA non-B27 types, the pathogenic site of the molecule is probably situated on the part of the molecule which is equal for all HLAB27 subtypes and different from all HLAnon-B27 types. Comparison of the amino acid residues of the characterised class I molecules showed that only the amino acid residue 70 is unique for all B27 subtypes and different from all HLA-non-B27 types. ${ }^{17}$ However, the resi-

$$
\text { HLA - Class } 1 \quad \text { HLA - B27 }
$$

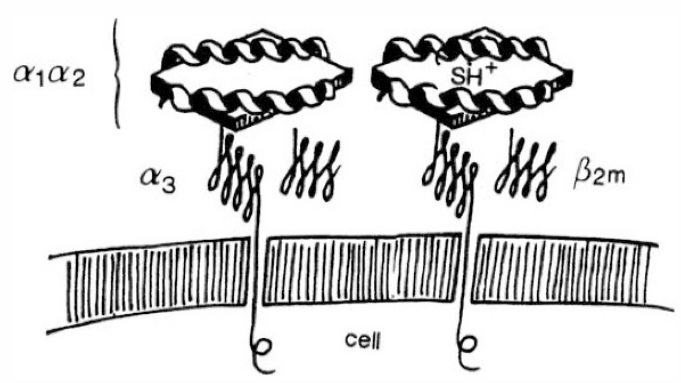

Fig. 4. HLA-B27 is different from all other HLA class I molecules by its lysin with a positive charge on position 70 . The cystein with a free $S H$ group is rarely seen in other HLA class I molecules (only B14 and Bw65 show a cystein on this position) (with permission of $\mathrm{J}$ Head and Neck Pathol). ${ }^{2}$ 
dues $9,45,67,70,71$ and 97 are also conserved in the B27 subtypes and are different from the HLA non-B27 types. ${ }^{18}$ This might indicate a region of the molecule which is prone to bind certain peptides in a typical way. The cystein on place 67 is especially interesting. The free $\mathrm{SH}$ group of this amino acid only is also found on HLA-B14 and HLA-Bw65 (Fig. 4). ${ }^{17,18}$

Most HLA class I molecules reach the cell surface in combination with a proper peptide which is of self or viral origin. It may be supposed that in the anterior eye during a certain viral infection particular peptides become available which fit well in the B27 groove forming a combination which is recognised by individuals with a certain genetic make-up of the $T$ cell receptor on cytotoxic $T$ cells. This supposition indicates three fields for further study. First, is AAU associated with certain viral infections? Secondly, do cells of the anterior eye present autologous or viral peptides via HLA-B27 in a particular way? Thirdly, do B27 ${ }^{+}$AAU patients show particular genetic markers on the $T$ cell receptors of their cytotoxic $\mathrm{T}$ cells?

The above does not mention the existing finding that HLA-B27 molecules have a certain amino acid sequence in common with both Klebsiella nitrogenase and Yersinia. ${ }^{19}$ Even if this should lead to a cross reactivity of antibodies to enterobacteria directing their activity also to HLA-B $27^{+}$cells, it is difficult to imagine that such an activity would result especially in arthritis and anterior uveitis.

The author wishes to thank Ms C. A. Lips for helping with the preparation of this manuscript.

\footnotetext{
References

${ }^{1}$ Feltkamp TEW: New views on B27 associated diseases. Neth J Med 1989, 35: 119-22.

${ }^{2}$ Feltkamp TEW: HLA and eye diseases. $J$ Head and Neck Pathol 1990, 9: 21-6.

${ }^{2}$ Tirawi JL and Terasaki PI: HLA and disease associations. New York, Springer Verlag, 1985:

${ }^{4}$ Priem HA, Kijlstra A, Nones L, Baarsma GS, De Laey JJ, Oosterhuis JA: HLA typing in birdshot
}

chorioretinopathy. Am J Ophthalmol 1988, 105: 182-5.

${ }^{5}$ Suchman AL and Dolan JG: Odds and likelihood ratios. In: Grimer PF, Panzer RJ, Greenland P (eds). Clinical diagnosis and the laboratory. Year Book Medical Publishers, Chicago 1986: 36.

${ }^{6}$ Fagan TJ: Nomogram for Bayes's theorem. N Engl J Med 1975, 293: 257.

${ }^{7}$ Feltkamp TEW: HLA and uveitis. Int Ophthalmol 1990 (in press).

${ }^{8}$ Rothova A, Van Veenendaal WG, Linssen A, Glasius E, Kijlstra A, de Jong PTVM: Clinical features of acute anterior uveitis. Am J Ophthalmol 1987, 103: 137-45.

${ }^{9}$ Saari KM: Acute anterior uveitis. In: Saari KM (ed). Uveitis update, Amstedam, 1984: 91-5.

${ }^{10}$ Linssen A, Dekker-Saeys AJ, Dijkstra PF, Rothova A, Kruit PJ, Bakker M, Kijlstra A, Feltkamp TEW: The use of HLA-B27 as a diagnostic and prognostic aid in acute anterior uveitis (AAU) in the Netherlands. Doc Ophthalmol 1987, 64: 217-23.

${ }^{11}$ Linssen A and Feltkamp TEW: B27 positive diseases versus B27 negative diseases. Ann Rheum Dis 1988, 47: 431-9.

${ }^{12}$ Ohno S: HLA and endogenous uveitis. In: Belfort RR, Petrilli AMN, Nussenblatt R (eds). World uveitis symposium. Sao Paulo, Livraria Roca 1989: 119-27.

${ }^{13}$ Linssen A: Acute anterior uveitis, ankylosing spondylitis and HLA-B27. Thesis, The Hague, Opmeer Offset B.V., 1987.

${ }^{14}$ Derhaag PJFM, Linssen A, Broekema N, de Waal LP, Feltkamp TEW: A family study of the inheritance of HLA-B27 positive acute anterior uveitis. Am J Ophthalmol 1988, 105: 603-6.

${ }^{15}$ Derhaag PJFM, van der Horst AR, de Waal LP, Feltkamp TEW: HLA-B $27^{+}$acute anterior uveitis and other antigens of the major histocompatibility complex. Invest Ophthalmol Vis Sci 1989, 30: 2160-4.

${ }^{16}$ Linssen A, Rothova A, Broekema N, Derhaag PJFM, Luyendijk L, de Lange GG, van Eede PH, van Leeuwen AM, Frants R, Kruit PJ, Baarsma GS, Kijlstra A, Feltkamp TEW: Genes on chromosome $14 \mathrm{q}$ and their role in the pathogenesis of HLA-B27 associated diseases. Clin Exp Rheumatol 1987, 5 (suppl. 1): 89-95.

${ }^{17}$ Derhaag PJFM, de Waal LP, Linssen A, Feltkamp TEW: Acute anterior uveitis and HLA-B27 subtypes. Invest Ophthalmol Vis Sci 1988, 29: 1137-40.

${ }^{18}$ Benjamin R and Perham P: Guilt by association: HLA-B27 and ankylosing spondylitis. Immunology today 1990, 11: 137-42.

${ }^{19}$ Yu DTY, Choo SY, Schaack T: Molecular mimicry in HLA-B27 related arthritis. Ann Inern Med 1989, 111: 581-91. 